\title{
Handedness and gender influence blood pressure in young healthy men and women: A pilot study
}

\author{
${ }^{1}$ Rueda I, ${ }^{1}$ Banegas I, ${ }^{1}$ Prieto I, ${ }^{1}$ Wangensteen R, ${ }^{1}$ Segarra AB, ${ }^{1}$ Villarejo AB, \\ ${ }^{2}$ De Gasparo M, ${ }^{3}$ Luna JD, ${ }^{4}$ Vives F, ${ }^{5}$ Ruiz-Bailen M, ${ }^{1}$ Ramirez-Sanchez M \\ ${ }^{1}$ Unit of Physiology, Department of Health Sciences, University of Jaen, Spain; \\ ${ }^{2}$ Cardiovascular \& Metabolic Syndrome Adviser, Rossemaison, Switzerland; \\ ${ }^{3}$ Department of Biostatistic, Medical School, University of Granada, Granada, Spain; \\ ${ }^{4}$ Instituto de Neurociencia 'Federico Oloriz', University of Granada, Granada, Spain; \\ ${ }^{5}$ Intensive Care Unit, Critical Care and Emergency Department, Medical-Surgical University \\ Hospital of the Jaen Hospital Complex \\ E-mail: msanchez@ujaen.es
}

Objective. The type and level of sex steroids influence blood pressure (BP). It has been suggested that functional brain asymmetries may be influenced by sex hormones. In addition, there are inter-arm differences in BP not yet related with handedness. In this study, we hypothesize a possible association between sex hormones, handedness, and inter-arm differences in blood pressure.

Methods. To analyze this hypothesis, we measured BP in the left and right arm of the left and right handed adult young men and women in menstrual and ovulatory phase and calculated their mean arterial pressure (MAP).

Results. Significant differences depending on sex, arm, handedness or phase of the cycle were observed. MAP was mostly higher in men than in women. Remarkably, in women, the highest levels were observed in the left handed in menstrual phase. Interestingly, the level of handedness correlated negatively with MAP measured in the left arm of right-handed women in the ovulatory phase but positively with the MAP measured in the right arm of right-handed women in the menstrual phase.

Conclusions. These results may reflect an asymmetrical modulatory influence of sex hormones in BP control.

Key words: brain asymmetry, handedness, sex hormones, blood pressure

There are gender differences in blood pressure (BP), its levels being higher in men than in women through much of their life (Sandberg and Ji 2012). Although changes in BP throughout menstrual cycle are contradictory (Dunne et al. 1991; Minson et al. 2000), the influence of the type and level of sex hormones on BP is clearly demonstrated (Dubey et al. 2002). Inter-arm differences in BP are frequent in clinical practice and this may be associated with cardiovascular risk (Clark 2015), but the etiology for such difference in the clinic is not clearly established. In addition, inter-arm BP differences were also described in healthy subjects (Grossmanet al. 2013), but the possible relationship with the level of handedness was not investigated. The predominance of the strength and skill of one hand over the other is considered the most striking functional asymmetry in humans (McManus 2002).It has been proposed that the brain and cardiovascular functions are reciprocally and asymmetrically interconnected (Banegas 
et al. 2011; Segarra et al. 2013). In addition, there are gender differences in functional brain asymmetries that are modified in women throughout the menstrual cycle (Weis and Hausmann 2010).This background may suggest that sex hormones may modulate BP and brain lateralized functions. We hypothesize an association between sex hormones, handedness, and BP. Therefore, we designed a study in which the levels of BP in the left and right arm of left and right handed young adult men and women (in the menstrual and ovulatory phase) were determined. Both phases were selected because of their radical opposite hormonal levels.

\section{Materials and Methods}

Ethics. The ethics committee for human research of the University of Jaen (CEIH 090414-1) approved all procedures used in this investigation (in advance). The study was conducted in accordance with the Declaration of Helsinki. All procedures were carried out with the adequate understanding and written informed consent of the participants.

Participants. The groups of young men and women that voluntarily participated in this study were the following:

1. Right-handed men (RHM; $n=13 ; 21.3 \pm 0.58$ years old);

2. Left-handed men (LHM; $n=12 ; 21.4 \pm 0.39$ years old);

3. Right-handed women (RHW; $\mathrm{n}=11 ; 20.8 \pm 0.44$ years old);

4. Left-handed women (LHW; $n=10 ; 21 \pm 0.42$ years old).

The level of handedness was determined by the Edinburgh Handedness Inventory (Oldfield, 1971) which give values from -1 (stronger left-handedness) to +1 (stronger right-handedness). All subjects were university students and self-reported to be non-smokers, non-consumers of alcohol and not under medication. All young women self-reported to have regular menstrual cycles of 28 days with a clear knowledge of their day of ovulation. In young women, BP was recorded in the menstrual ( $1^{\text {st }}$ or $2^{\text {nd }}$ day of bleeding) (RHWM or LHWM) and during the ovulatory phase (RHWO or LHWO).

Blood pressure measurement. Blood pressure was measured in all the subjects in the sitting position following $5 \mathrm{~min}$ of rest, with the arms resting on the table at the heart level, using an automatic arm sphygmomanometer (Pic indolor diagnostic CS 410, Italy).Values were obtained in one arm (either right or left, without preference) and sequentially (at least 3 min interval), in the other arm by performing three consecutive measurements (1 min interval between each). The average of the last two measures was selected as final data for analysis (Grossman et al. 2013).

Basal body temperature measurement. The women measured their basal body temperature (BBT) from the $1^{\text {st }}$ day of cycle ( $1^{\text {st }}$ day of bleeding), every morning before getting out of the bed, using a digital thermometer. When a sudden rise of BBT was recorded (always occurring the day 14 of cycle), this was considered as sign of the ovulatory phase. A shift in BBT from the $1^{\text {st }}$ day of cycle is considered reliable as sign for ovulatory phase with a probability of being within \pm 1 day of the true ovulation day (Dunson et al. 1999). The participating women have regular menstrual cycles and they have repeatedly confirmed their regular days of ovulation. Recording were made in the morning over a 3 months period from March to June.

Statistical analysis. To facilitate the understanding of the results, the analysis was limited to the study of differences in mean arterial pressure (MAP), calculated as $[(2 \mathrm{x}$ diastolic $)+$ systolic $] / 3$ (Klabunde 2015). The experimental design was following: four factors were considered, three of them were fix effects (sex, laterality and arm) and one random effect (subject). Sex had two levels: male and female but in the case of female two groups were considered: ovulation and menstruation. Therefore, three groups were considered: male, female in ovulation and female in menstruation. Handedness had two levels, right-handed and left-handed and the arm, a repeated measures factor with two levels: left and right. The random effect factor was nested in the interaction of sex by handedness. The design was analyzed using the corresponding ANOVA's table looking first to the interaction of sex-handednessarm. If significant, subsequent pairwise comparisons using Bonferroni's penalization were performed (Table 1, Figure 1, Figure 2). To study the association between level of handedness and the rest of parameters, Pearson's coefficient of correlation was computed (figure 3). All computing was made using Stata 11.3 and the ANOVA and margins packages from it. $\mathrm{P}$ values below 0.05 were considered significant.

\section{Results}

Level of handedness. The level of handedness was higher $(p<0.01)$ in right-handed than the left-handed men (Figure 1). No differences between right-handed men and right-handed women or between left-handed men and left-handed women were observed. No 
differences were observed when the level of handedness was compared between left-handed and righthanded women.

Inter-arm differences. Although MAP was higher in the left arm of LHM, RHM, and LHWO and in the right arm of RHWO, LHWM, and RHWM, the only the inter-arm significant difference was observed in the group of RHWO $(\mathrm{p}=0.02)$ (Table 1$)$.

Left arm. Mean arterial pressure determined in the left arm demonstrated fewer differences between groups than the MAP determined in the right arm. LHM was significantly higher than RHWO $(\mathrm{p}<0.01)$ and RHWM $(\mathrm{p}<0.05)$ (Figure 2).

Right arm. Mean arterial pressure determined in the right arm demonstrated significantly higher levels in LHM than LHWO $(\mathrm{p}<0.001)$ and RHWM $(\mathrm{p}<0.05)$. RHM was significantly higher than LHWO $(\mathrm{p}<0.05)$. LHWO was significantly lower than RHWO $(\mathrm{p}<0.05)$ and LHWM $(\mathrm{p}<0.01)$ (Figure 2).

Analysis of regression. A significant negative correlation between the level of handedness and the MAP measured in the left arm of right-handed women in the ovulatory phase was observed $(r=-0.672$, $\mathrm{p}=0.01$ ): the higher level of handedness, the lower level of MAP and vice-versa (Figure 3). This indicates that the more the right-handed women is using her right hand, the lower the MAP in the left arm at ovulation. In contrast, a significant positive correlation between the level of handedness and the MAP measured in the right arm of right-handed women in the menstrual phase was observed $(\mathrm{r}=+0.528, \mathrm{p}=0.04)$ : the higher level of handedness, the higher level of MAP and vice-versa (Figure 3). In this case, the more the right-handed women is using her right hand, the higher the MAP in the right arm at menstruation.

\section{Discussion}

The present data demonstrate the existence of inter-arm and handedness differences at the level of MAP, which, depend on the gender, and the status of the ovarian cycle. Grossman et al. (2013) have concluded that inter-arm differences are common in healthy young subjects and that these differences are not dependent on which arm was measured first. However, they did not consider gender, handedness or phase of ovarian cycle. Therefore, to our knowledge this is the first report that describes a possible connection between all of these variables.

Mean arterial pressure was mostly higher in men than in women, but remarkably in women the highest levels of MAP (determined in both left and right arms) were observed in the group of left handed in
Table 1

Inter arm differences in Mean Arterial Pressure (mean \pm S.E.M.) in the groups studied

\begin{tabular}{lccc}
\hline & Left Arm & Right Arm & p-value \\
\hline LHM & $88.6 \pm 3.7$ & $87.7 \pm 2.7$ & 0.82 \\
RHM & $85.6 \pm 4.4$ & $82.5 \pm 2.8$ & 0.24 \\
LHWO & $78.3 \pm 3.6$ & $72.3 \pm 2.8$ & 0.23 \\
RHWO & $75.7 \pm 2.2$ & $80.9 \pm 2.7$ & $0.02^{*}$ \\
LHWM & $82.3 \pm 4.7$ & $85.6 \pm 3.4$ & 0.34 \\
RHWM & $76.9 \pm 1.9$ & $79.3 \pm 2.1$ & 0.18 \\
\hline
\end{tabular}

Abbreviations: LHM - left-handed men; RHM - right-handed men; LHWO - left-handed women ovulation; RHWO - righthanded women ovulation; LHWM - left-handed women menstruation; RHWM - right-handed women menstruation.

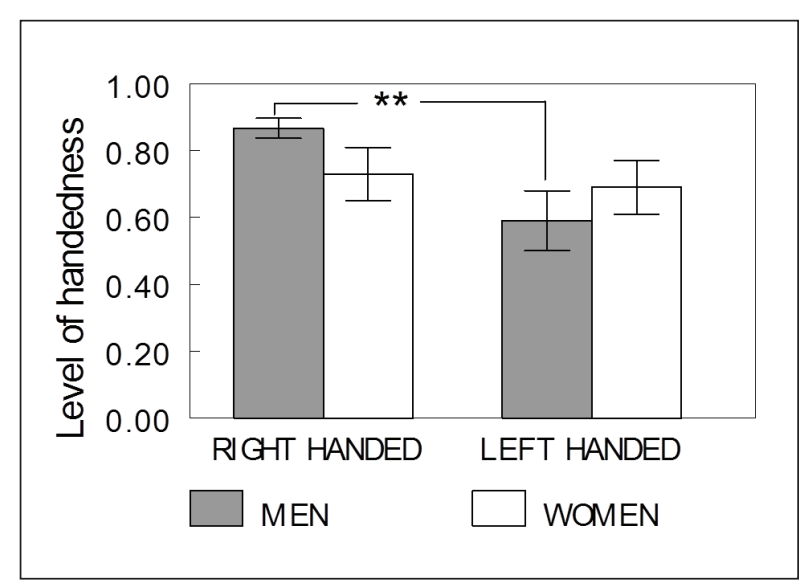

Figure 1. Levels of handedness determined by the Edinburgh handedness inventory in young men and women right- and left-handed. Data are presented as mean \pm SEM $\left({ }^{* *} \mathrm{p}<0.01\right)$.

menstrual phase. Since, it has been reported that lefthanded people have a greater probability to suffer of specific health disorders such as hypertension than right-handed people (Bryden et al. 2005), this condition should be further analyzed not only throughout the fertile life of left-handed healthy women but also in hypertensive ones and in situations of cardiovascular risk.

There are conflicting results regarding the existence of BP differences throughout menstrual cycle. Whereas some authors did not found changes between luteal and follicular phase (Minson et al. 2000), others have found higher levels of BP in the menstrual phase than in the luteal one (Dunne et al. 1991).Changes in the plasmatic levels of androgens 

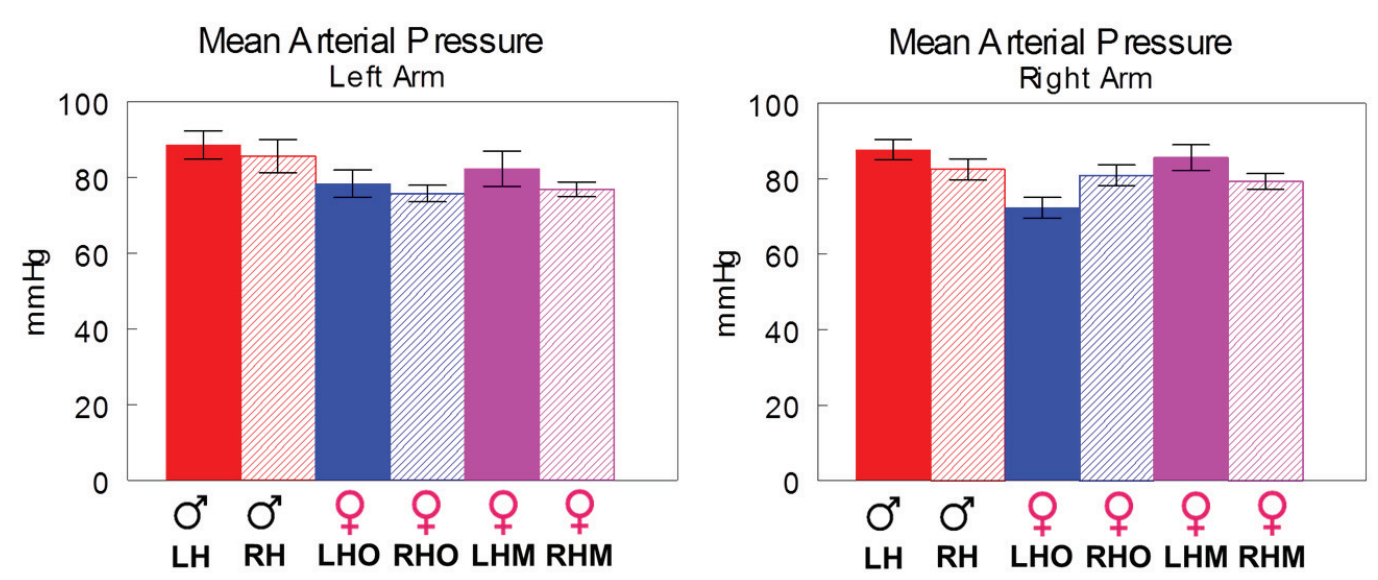

\begin{tabular}{|c|c|c|c|c|c|c|}
\hline & ${ }_{\text {LH }}^{\circ}$ & $\begin{array}{l}O^{*} \\
\mathrm{RH}\end{array}$ & $\begin{array}{l}\text { P } \\
\text { LHO }\end{array}$ & $\begin{array}{c}\text { OP } \\
\text { RHO }\end{array}$ & $\begin{array}{l}\text { P } \\
\text { LHM }\end{array}$ & $\begin{array}{c}\text { P } \\
\text { RHM }\end{array}$ \\
\hline $\begin{array}{l}\mathrm{O}^{\prime \prime} \\
\mathrm{LH}\end{array}$ & 1 & N.D. & N.D. & $<0.01$ & N.D. & $<0.05$ \\
\hline $\begin{array}{l}\sigma^{x} \\
R H\end{array}$ & & 1 & N.D. & N.D. & N.D. & N.D. \\
\hline$\underset{\text { LHO }}{\text { Oे }}$ & & & 1 & N.D & N.D & N.D. \\
\hline 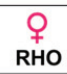 & & & & 1 & N.D. & N.D. \\
\hline 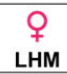 & & & & & 1 & N.D. \\
\hline$\underset{\text { RHM }}{\text { P }}$ & & & & & & 1 \\
\hline
\end{tabular}

\begin{tabular}{|c|c|c|c|c|c|c|}
\hline & OH & $\begin{array}{l}O^{*} \\
\mathrm{RH}\end{array}$ & $\begin{array}{c}\text { P } \\
\text { LHO }\end{array}$ & $\begin{array}{l}\text { P } \\
\text { RHO }\end{array}$ & 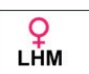 & $\begin{array}{c}\text { P } \\
\text { RHM }\end{array}$ \\
\hline $\mathrm{O}_{\mathrm{LH}}$ & 1 & N.D. & $<0.001$ & N.D. & N.D. & $<0.05$ \\
\hline $\begin{array}{l}O^{\prime \prime} \\
\mathrm{RH}\end{array}$ & & 1 & $<0.05$ & N.D. & N.D. & N.D. \\
\hline $\begin{array}{c}\text { O } \\
\text { LHO }\end{array}$ & & & 1 & $<0.05$ & $<0.01$ & N.D. \\
\hline $\begin{array}{c}\text { O } \\
\text { RHO }\end{array}$ & & & & 1 & N.D. & N.D. \\
\hline $\begin{array}{c}\stackrel{9}{9} \\
\text { LHM }\end{array}$ & & & & & 1 & N.D. \\
\hline $\begin{array}{c}q \\
\text { RHM }\end{array}$ & & & & & & 1 \\
\hline
\end{tabular}

Figure 2. Levels of mean arterial pressure measured in the left and right arm of right- and left-handed young adult men and young adult women in menstruation and ovulatory phase. Data are presented as mean \pm SEM. The level of significance (p) of the comparisons between groups is indicated below each figure. Abbreviations: LH - left-handers; RH - right-handers; LHO - left-handed women ovulation; RHO - right-handed women ovulation; LHM - left-handed women menstruation; RHM - right-handed women menstruation; N.D. - no difference.

throughout the menstrual cycle, possibly related to menstrual mood changes (Duskova et al. 2011), could be related with modifications in BP. It should also be noted that women have a higher rate of cerebral blood flow than men (Gur and Gur 1990). Further, the degree of hemispheric flow asymmetry was influenced by sex and handedness: females have a higher rate of blood flow per unit weight of brain, and left-handers a greater percentage of fast-clearing tissue, presumably gray matter (Gur et al. 1982). In addition, a cyclic vasodilatation of the vasculature of the right hemisphere across the menstrual cycle has been reported (Krejza et al. 2013). However, to our knowledge, no studies differentiating left- and right-handed women during the menstrual cycle have been performed.

Previous studies in animal models have suggested the existence of asymmetries in the cardiovascular control, which may be due in part to asymmetries in the autonomic innervations of heart and vessels (Banegas et al. 2011; Segarra et al. 2013). This may be linked to modifications in functional cerebral asymmetries in fine motor coordination, which were affected by sex hormonal changes during the menstrual cycle (Bayer and Hausmann 2012).

Taking together, the present results suggest a connection between the existence of differences in BP in inter-arm measurements, handedness, gender, and phase of the ovarian cycle, which may suggest an asymmetrical modulatory influence of sex hormones in BP control.

\section{Study limitations}

Although the population analyzed was small and the level of handedness was obtained through questionnaire (which could be considered as a qualitative 


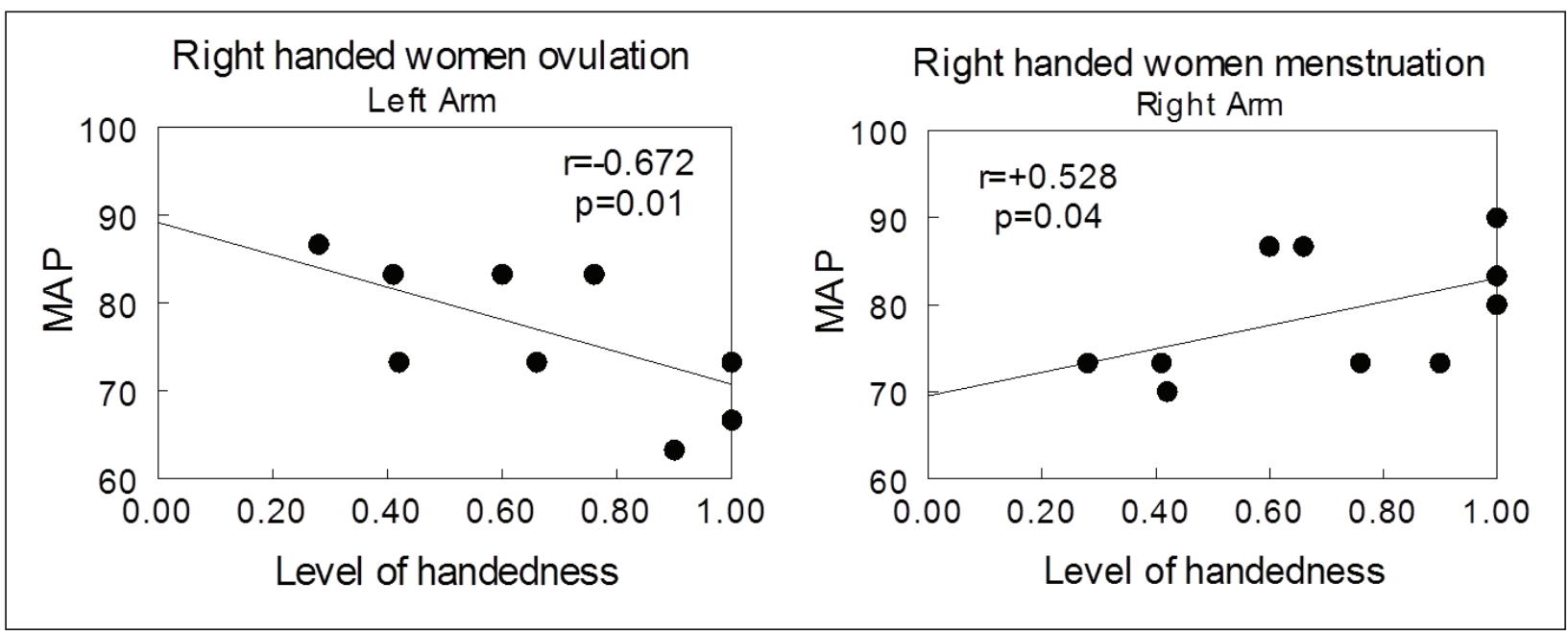

Figure 3. Significant correlations between the level of handedness and the mean arterial pressure (MAP) (mmHg) measured in the left and right arm of right-handed women in the ovulatory and menstrual phase, respectively.

value), the groups were very homogeneous and constituted for healthy non-hypertensive young adults. Given very little variability between the individuals involved, in this study, there were clear significant differences between groups. Although some authors have recommend to measure BP simultaneously in both arms (Verberk et al. 2011), this is certainly not a practical method in a clinical setting. Other authors have also used sequential measurements to evaluate inter-arm differences in BP (Grossman et al. 2013). Finally, it should be taken into account that brain asymmetry and the level of handedness may change with the ovarian cycle (Weis and Hausmann 2010; Bayer and Hausmann 2012).

\section{Conclusion}

In conclusion, the present report is a pilot study that strongly suggests a functional interaction between handedness, BP, sex, and phase of the ovarian cycle, which may involve an asymmetrical modulation of BP control by sex hormones.

\section{Acknowledgements}

We would like to thank to the study participants for their time and effort. This work was supported by the research group "Neuroendocrinology and Nutrition" BIO-221.

\section{References}

Banegas I, Prieto I, Segarra AB, Duran R, Vives F, Alba F, Luna JD, de Gasparo M, Wangesteen R, Ruiz-Bailen M, Ramirez-Sanchez M. Blood pressure increased dramatically in hypertensive rats after left hemisphere lesions with 6-hydroxydopamine. Neurosci Lett 500, 148-150, 2011.

Bayer U, Hausmann M. Menstrual cycle-related changes of functional cerebral asymmetries in fine motor coordination. Brain Cogn 79, 34-38, 2012.

Bryden PJ, Bruyn J, Fletcher P. Handedness and health: an examination of the association between different handedness classifications and health disorders. Laterality 10, 429-440, 2005.

Clark CE. Difference in blood pressure measurements between arms: methodological and clinical implications. Curr Pharm Des 21, 737-743, 2015.

Dubey RK, Oparil S, Imthurn B, Jackson EK. Sex hormones and hypertension. Cardiovasc Res 53, 688-708, 2002.

Dunne FP, Barry DG, Ferriss JB, Grealy G, Murphy D. Changes in blood pressure during the normal menstrual cycle. ClinSci (Lond) 81, 515-518, 1991.

Dunson DB, Baird DD, Wilcox AJ, Weinberg CR. Day-specific probabilities of clinical pregnancy based on two studies with imperfect measures of ovulation. Hum Reprod 14, 1835-1839, 1999. 
Duskova M, Simunkova K, Hill M, Starka L. 7-hydroxylated derivatives of dehydroepiandrosterone as possibly related to menstrual mood change in healthy women. Endocr Regul 45, 131-137, 2011.

Grossman A, Prokupetz A, Gordon B, Morag-Koren N, Grossman E. Inter-arm blood pressure differences in young, healthy patients. J ClinHypertens (Greenwich) 15, 575-578, 2013.

Gur RC, Gur RE, Obrist WD, Hungerbuhler JP, Younkin D, Rosen AD, Skolnick BE, Reivich M. Sex and handedness differences in cerebral blood flow during rest and cognitive activity. Science 217, 659-661, 1982.

Gur RE, Gur RC. Gender differences in regional cerebral blood flow. Schizophr Bull 16, 247-254, 1990.

Klabunde RE. Cardiovascular physiology concepts—-mean arterial pressure. Lippincott Williams \& Wilkins, 2011. Available at: http://www.cvphysiology.com/Blood Pressure/BP006.htm.

Krejza J, Rudzinski W, Arkuszewski M, Onuoha O, Melhem ER. Cerebrovascular reactivity across the menstrual cycle in young healthy women. Neuroradiol J 26, 413-419, 2013.

McManus C. Right Hand, Left Hand. The Origins of Asymmetry in Brains, Bodies, Atoms and Cultures.Weidenfeld \& Nicolson, London, 2002.

Minson CT, Halliwill JR, Young TM, Joyner MJ. Influence of the menstrual cycle on sympathetic activity, baroreflex sensitivity, and vascular transduction in young women. Circulation 101, 862-868, 2000.

Oldfield RC. The assessment and analysis of handedness: the Edinburgh inventory. Neuropsychologia 9, 97-113, 1971.

Sandberg K, Ji H. Sex differences in primary hypertension. Biol Sex Differ 3, 7, 2012.

Segarra AB, Prieto I, Banegas I, Villarejo AB, Wangensteen R, de Gasparo M, Vives F, Ramirez-Sanchez M. The brain-heart connection: frontal cortex and left ventricle angiotensinase activities in control and captopriltreated hypertensive rats-a bilateral study. Int J Hypertens 2013:156179, 2013.

Verberk WJ, Kessels AG, Thien T. Blood pressure measurement method and inter-arm differences: a meta-analysis. Am J Hypertens 24, 1201-1208, 2011.

Weis S, Hausmann M. Sex hormones: modulators of interhemispheric inhibition in the human brain. Neuroscientist $16,132-138,2010$. 